11 Allen SC, Yeung P. Inability to draw intersecting pentagons as a predictor of unsatisfactory spirometry technique in elderly hospital inpatients. Age Ageing 2006; 35: 304-306.

12 Dodd JW, Charlton RA, van den Broek MD, et al. Cognitive dysfunction in patients hospitalized with acute exacerbation of COPD. Chest 2013; 144: 119-127.

13 Clini EM, Beghé B, Fabbri LM. Chronic obstructive pulmonary disease is just one component of the complex multimorbidities in patients with COPD. Am J Respir Crit Care Med 2013; 187: 668-671.

14 American Geriatrics Society Expert Panel on the Care of Older Adults with Multimorbidity. Guiding principles for the care of older adults with multimorbidity: an approach for clinicians. J Am Geriatr Soc 2012; 60: E1-E25.

\title{
Increased wheezing risk with diesel exposure among children of younger mothers
}

\author{
To the Editor:
}

Lower respiratory tract illnesses (LRIs) are the largest cause of mortality among young children worldwide [1], and are associated with altered lung function, immune system development and respiratory disease in adulthood [2,3]. Several studies have demonstrated associations between wheezing LRIs in early life and exposure to diesel traffic related air pollutants (D-TRAP) $[1,4,5]$. We, along with others, have previously demonstrated that younger maternal age at birth is also a risk factor for wheezing LRIs in the first year of life $[6,7]$. Why children of younger mothers are more susceptible is unknown, but both altered responses to environmental challenges in their offspring due to maternal immaturity [6] and increased socioeconomic and environmental risks have been proposed as causes [8].

We postulated that children of younger mothers are more susceptible to environmental exposures than children of older mothers. To test this hypothesis, we used data from the Tucson Children's Respiratory Study, a longitudinal birth cohort designed to investigate risk factors for LRIs in early childhood and chronic lung disorders later in life $[9,10]$. Through age 3 years, LRIs were diagnosed by study physicians who documented wheeze [10]. Parents were asked if their child had active wheeze during the past year at 6 years. Four wheezing phenotypes were defined: never, transient-early (only to age 3 years), late-onset (by age 6 but not by age 3 years), and persistent (by age 3 and 6 years) [11]. The study was approved by the University of Arizona Human Subjects Committee. Informed consent was obtained from a parent of a participating child.

We estimated D-TRAP exposure for each enrolment address using CAL3QHC, a Gaussian line-source dispersion model [12], that estimates traffic pollutant concentrations as a function of distance to roadway, traffic volume, wind speed and direction, atmospheric stability class, and vehicle emissions. We only used highways in our analysis, as they represent the primary source of diesel exhaust in Tucson, AZ, USA. Roadway and meteorological data corresponding to each participant's season of birth were obtained from the Arizona Department of Transportation and the National Weather Service. Emissions factors were computed with the United States Environmental Protection Agency's MOBILE 6.2 model for PM2.5 by diesel vehicle class.

We geocoded each participant's enrolment address using ArcGIS 10 (ESRI, Redlands, CA, USA), and obtained D-TRAP exposure for these coordinates with CAL3QHC. D-TRAP estimates represent seasonal exposures to a mixture of air pollutants from proximity to highway diesel traffic emissions independent of other diesel exhaust sources, and are interpreted as a unitless index.

Because our outcome was a count variable (i.e. number of wheezing LRIs) and $62 \%$ had no wheezing LRI (mean 0.62, variance 1.00), we used a negative binomial regression to account for over-dispersion in assessing the relationship between D-TRAP exposure and wheezing LRI events. Multinomial regression was used to assess associations with wheezing phenotypes. Interaction terms were included to assess effect modification. We examined pairwise associations between D-TRAP exposure, maternal age, and wheezing LRIs, with potential confounders (i.e. sex, ethnicity, maternal education, household cooling methods, older children in the home, marital status and census tract socioeconomic status, among others). We used the robust cluster estimator of variance to account for potential clustering by census tract. To assess multi-collinearity, we calculated the variance inflation factor for the final adjusted models. STATA 13.0 (StataCorp, College Station, TX, USA) was used for all analyses. 
Of the original 1246 children enrolled, 825 had enrolment addresses from which D-TRAP exposure could be estimated and were followed by study physicians for the first 3 years of life: $23.3 \%$ had one wheezing LRI; $8.5 \%$ had two; and $6.1 \%$ had three to five. There was no difference in the distribution of D-TRAP exposure between children included in the analyses and those with incomplete follow-up ( $p=0.32$ ). Included participants were more likely to be White or Hispanic, to have older mothers with $>12$ years of schooling, and to live in a house with evaporative cooling.

Each log increase of D-TRAP exposure was associated with an increased incidence rate ratio for wheezing LRIs (table 1). Children of mothers $<21$ or 21-25 years old had a significantly higher incidence rate ratio per log increase of D-TRAP exposure (table 1). D-TRAP exposure was associated with transient wheezing among children with mothers <21 years old (OR 2.55, 95\% CI 1.04-6.24) and 21-25 years old (OR 1.75, 95\% CI 1.17-2.60), but not among children with older mothers (OR 0.98, 95\% CI 0.77-1.26 for 2630 years old and OR 1.07, 95\% CI $0.79-1.47$ for $>30$ years old). Late-onset and persistent wheezing phenotypes were not associated with D-TRAP exposure.

Increased D-TRAP exposure at enrolment and younger maternal age were both associated with Hispanic ethnicity, less maternal education, or living in a census tract with low socioeconomic status. Younger maternal age was also associated with marital status, fewer older children in the home, and household use of evaporative cooling. However, results remained consistent after adjustment for these potential confounders (table 1).

To our knowledge, this is the first study demonstrating that younger maternal age modifies the effect of air pollution on children's respiratory outcomes. Factors directly or indirectly related to maternal age such as biological factors associated with lung growth may make their infants more susceptible to wheeze with increased D-TRAP exposure. Younger mothers are at increased risk of preterm delivery, with lower birth weight or small for gestational age babies, independent of socioeconomic status [13], all of which are risk factors for reduced lung function later in life, although that did not account for the relationships reported here.

Prenatal exposures to particulate matter are more strongly associated with recurrent wheezing LRIs than childhood exposures [4]. Furthermore, younger maternal age modifies the association of prenatal carbon monoxide exposure and low birth weight [14]. These studies suggest that younger mothers may be more susceptible to air pollution exposures, perhaps due to their own physical immaturity while the child is in utero.

Maternal age may be a proxy for an unknown social or environmental factor not considered resulting in residual confounding, such as lack of prenatal care [15]. Differential exposure misclassification by maternal age could also have affected our results. Younger mothers are more likely than older mothers to work or attend school near their homes, and thus may be more accurately characterised by air pollution levels at their home address [14].

The strength of our study is that all LRIs were assessed prospectively by study physicians using predefined criteria in a non-selected cohort. However, recruitment through a health maintenance organisation probably

TABLE 1 Incidence rate ratio (IRR) for wheezing lower respiratory tract illnesses in the first 3 years of life by 1 ) diesel traffic related air pollutant (D-TRAP) exposure, 2) maternal age, and 3) D-TRAP exposure by maternal age category

\begin{tabular}{|c|c|c|c|c|c|c|c|}
\hline Exposure & Subjects $n$ & \multicolumn{3}{|c|}{ Crude } & \multicolumn{3}{|c|}{ Adjusted $^{\#}$} \\
\hline Model 1: D-TRAPI & 822 & 1.13 & $1.03-1.23$ & 0.009 & 1.07 & $0.98-1.17$ & 0.13 \\
\hline \multicolumn{8}{|c|}{ Model 2: maternal age } \\
\hline$<21$ years & 42 & 1.01 & $0.66-1.54$ & 0.96 & 1.06 & $0.70-1.63$ & 0.77 \\
\hline $21-25$ years & 238 & 1.33 & $1.01-1.76$ & 0.04 & 1.35 & $1.04-1.76$ & 0.02 \\
\hline $26-30$ years & 316 & 1.14 & $0.88-1.47$ & 0.34 & 1.20 & $0.93-1.56$ & 0.17 \\
\hline$<21$ years & 42 & 1.35 & $1.05-1.74$ & 0.02 & 1.31 & $1.02-1.67$ & 0.03 \\
\hline $21-25$ years & 238 & 1.33 & $1.14-1.57$ & $<0.001$ & 1.25 & $1.07-1.45$ & 0.005 \\
\hline $26-30$ years & 316 & 0.96 & $0.82-1.13$ & 0.63 & 0.94 & $0.81-1.11$ & 0.47 \\
\hline$>30$ years & 229 & 0.97 & $0.80-1.17$ & 0.75 & 0.92 & $0.75-1.12$ & 0.42 \\
\hline
\end{tabular}

Results are from negative binomial regression models, and statistically significant associations are indicated in boldface. An interaction term was included in model 3 with D-TRAP exposure and maternal age, evaluated with the Wald test (chi-squared 16.94, degrees of freedom 3 , $\mathrm{p}=0.0007)$. \# : adjusted for child ethnicity (variance inflation factor (VIF) 1.19), older children in the household (VIF 1.10), household cooling methods (VIF 1.03) and census tract socioeconomic status (VIF 1.23). VIF was 1.11 and 1.13 for D-TRAP and maternal age, respectively. ": IRR per log increase in D-TRAP exposure. 
under-represented children of low socioeconomic status [9]. Unfortunately, air pollution measurements were not taken at participants' homes, and adequate existing data corresponding to that time period (1980-1987) are unavailable. By modelling highway truck traffic emissions, the primary source of diesel exhaust in Tucson, we have probably identified the children chronically exposed to higher levels of D-TRAP. Greater exposure specificity would presumably lead to stronger associations than we have reported.

In summary, the association of wheezing LRIs with D-TRAP exposure was stronger in children of younger mothers, who were also more likely to have transient-early wheezing with increasing D-TRAP exposure. Biological and social risk factors associated with younger maternal age may explain these findings. Given that younger mothers are more likely to live in areas of increased diesel traffic exposure, targeting exposure prevention strategies specifically for children of younger mothers may be warranted.

卫EERpublications

Association of wheeze with diesel pollution exposure is stronger in children of younger mothers http://ow.ly/KMHTy

Paloma I. Beamer ${ }^{1,2,3}$, Nathan Lothrop ${ }^{2}$, Debra A. Stern ${ }^{1}$, Dean Billheimer, ${ }^{3,4}$ Anne L. Wright ${ }^{1}$ and Fernando D. Martinez ${ }^{1,3}$

${ }^{1}$ Arizona Respiratory Center, University of Arizona, Tucson, AZ, USA. ${ }^{2}$ Environmental Health Sciences, Mel and Enid Zuckerman College of Public Health, University of Arizona, Tucson, AZ, USA. ${ }^{3}$ Bio5 Institute, University of Arizona, Tucson, AZ, USA. ${ }^{4}$ Agricultural and Biosystems Engineering, College of Agriculture and Life Sciences, University of Arizona, Tucson, AZ, USA.

Correspondence: P.I. Beamer, Environmental Health Sciences, Mel and Enid Zuckerman College of Public Health, University of Arizona, 1295 N. Martin Ave., PO 245210, Tucson, AZ 85724, USA. E-mail: pbeamer@email.arizona.edu

Received: Sept 162014 | Accepted after revision: March 032015 | First published online: April 162015

Support statement: This work was supported by NIH grants ES006694, HL56177 and HL103970. The publication's contents are solely the responsibility of the authors and do not necessarily represent the official views of the National Institutes of Health. Funding information for this article has been deposited with FundRef.

Conflict of interest: Disclosures can be found alongside the online version of this article at erj.ersjournals.com

\section{References}

1 Mehta S, Shin H, Burnett R, et al. Ambient particulate air pollution and acute lower respiratory infections: a systematic review and implications for estimating the global burden of disease. Air Qual, Atmos Health 2013; 6: 69-83.

2 Narang I, Bush A. Early origins of chronic obstructive pulmonary disease. Semin Fetal Neonatal Med 2012; 17: $112-116$.

3 Puig C, Fríguls B, Gómez M, et al. Relationship between lower respiratory tract infections in the first year of life and the development of asthma and wheezing in children. Archivos de Bronconeumología (English Edition) 2010; 46: 514-521.

4 Jedrychowski WA, Perera FP, Majewska R, et al. Separate and joint effects of tranplacental and postnata inhalatory exposure to polycyclic aromatic hydrocarbons: prospective birth cohort study on wheezing events. Pediatr Pulmonol 2014; 49: 162-172.

5 MacIntyre EA, Gehring U, Molter A, et al. Air pollution and respiratory infections during early childhood: an analysis of 10 European birth cohorts within the ESCAPE Project. Environ Health Perspect 2014; 122: 107-113.

6 Martinez FD, Wright AL, Holberg CJ, et al. Maternal age as a risk factor for wheezing lower respiratory illnesses in the first year of life. Am J Epidemiol 1992; 136: 1258-1268.

7 Caudri D, Savenije OE, Smit HA, et al. Perinatal risk factors for wheezing phenotypes in the first 8years of life. Clin Exp Allergy 2013; 43: 1395-1405.

8 Lawlor DA, Mortensen L, Andersen AM. Mechanisms underlying the associations of maternal age with adverse perinatal outcomes: a sibling study of 264695 Danish women and their firstborn offspring. Int J Epidemiol 2011; 40: $1205-1214$

9 Taussig LM, Wright AL, Morgan WJ, et al. The Tucson children's respiratory study I. Design and implementation of a prospective study of acute and chronic respiratory illness in children. Am J Epidemiol 1989; 129: 1219-1231.

10 Wright AL, Taussig LM, Ray CG, et al. The Tucson children's respiratory study II. Lower respiratory tract illness in the first year of life. Am J Epidemiol 1989; 129: 1232-1246.

11 Martinez FD, Wright AL, Taussig LM, et al. Asthma and wheezing in the first six years of life. N Engl J Med 1995; 332: 133-138.

12 Schattanek G, Kahng E, Stratou T, et al. EPA User's Guide to CAL3QHC-A Modeling Methodology for Predicting Pollutant Concentrations Near Roadway Intersections. Chicago, US Environmental Protection Agency, 1990.

13 Fraser AM, Brockert JE, Ward RH. Association of young maternal age with adverse reproductive outcomes. $N$ Engl J Med 1995; 332: 1113-1118.

14 Ritz B, Yu F. The effect of ambient carbon monoxide on low birth weight among children born in southern California between 1989 and 1993. Environ Health Perspect 1999; 107: 17-25.

15 Kingston D, Heaman M, Fell D, et al. Comparison of adolescent, young adult, and adult women's maternity experiences and practices. Pediatrics 2012; 129: e1228-e1237. 